\title{
Etiological Profile of Patients Presenting with Lower Gastrointestinal Bleeding in Ibb Governorate-Yemen
}

\author{
Abdulgafoor Kassim, Khalid Al-Qubaty, Ramea Alathwary*, Sana Ameen \\ Internal Medicine, Faculty of Medicine, Taiz University, Taiz, Yemen \\ Email: a.algafoor@gmail.com,drkhaled52@yahoo.com, *alathwaryramea@gmail.com, sana.ameen38@yahoo.com
}

How to cite this paper: Kassim, A., Al-Qubaty, K., Alathwary, R. and Ameen, S. (2018) Etiological Profile of Patients Presenting with Lower Gastrointestinal Bleeding in Ibb Governorate-Yemen. Open Access Library Journal, 5: e4683.

https://doi.org/10.4236/oalib.1104683

Received: May 28, 2018

Accepted: June 18, 2018

Published: June 21, 2018

Copyright $\odot 2018$ by authors and Open Access Library Inc.

This work is licensed under the Creative Commons Attribution International License (CC BY 4.0).

http://creativecommons.org/licenses/by/4.0/

\begin{abstract}
Objectives: To investigate the causes of lower gastrointestinal bleeding (LGIB) in Yemeni patients and to compare our results with the results of other studies. Design: Prospective study of patients with overt LGIB during the period from April 2017 to March 2018. Setting: Specialized center of gastrointestinal and liver diseases in Ibb city, Yemen. Subjects \& Method: Consecutive patients who presented or referred to our center with LGIB to whom lower GI endoscopy was performed. Results: During the study period, we had 122 patients with LGIB, 72 were males and 50 were females, with male:female ratio of 1.4:1 The age ranged between 5 and 82 years and the mean age was $45 \pm 17.99$ years. The clinical presentations of our patients included hematochezia in $72.1 \%$, abdominal pain in $51.7 \%$, diarrhea in $43.3 \%$, pallor, and anemia in $40.2 \%$, weight loss in $39.3 \%$, constipation in $16.4 \%$, bloody diarrhea in $16.4 \%$, and melena in $5.7 \%$. The most common colonoscopic findings were hemorrhoids in $36.7 \%$ followed by colon cancer in $19.7 \%$ and nonspecific colitis in $15.6 \%$. Conclusion: Hemorrhoids and colon cancer were the most common causes of lower GI bleeding in our patients.
\end{abstract}

\author{
Subject Areas \\ Gastroenterology \& Hepatology \\ Keywords \\ LGIB, Etiology, Colonoscopy, Clinical Features, Yemeni Patients
}

\section{Introduction}

Lower gastrointestinal bleeding (LGIB) is bleeding arising below the ligament of Treitz [1] [2]. It accounts for about $20 \%$ of all cases of acute GI bleeding [3]. The 
incidence of LGIB ranges from 20.5 to 27 cases/100,000 adults [4], and increases with age and is more common in men than women [5] [6]. LGIB represents a significant cause of morbidity and mortality, It has an annual incidence of hospitalization of approximately $36 / 100,000$ population and the rate of hospitalization is even higher in the elderly with an overall mortality rate ranging from $2 \%$ to $4 \%$ [7] [8]. LGIB usually causes hematochezia, melena, or blood streaking of the stool [7] [8] [9]. Patients usually present with painless hematochezia and a decrease in hematocrit value, but without orthostasis [3] [8]. The etiology and the epidemiology of LGIB vary according to the environmental conditions depending upon the lifestyle, dietary habits, the prevalence of smoking, history of drug intake, age, the longevity of the population, etc. [10]. Diverticulosis coli is one of the most common causes of LGIB in the countries of Western Europe and the United States unlike in Asia, diverticulosis coli is uncommon and is much less responsible as a cause of LGIB where hemorrhoids is the commonest colonoscopic findings [6] [9] [11] [12]. Colonoscopy is the most convenient and effective preliminary investigation [1] [13] [14]. Actual visualization during the acute episode is uncommon because the view is poor. While some authors advocate early colonoscopy in an unprepared bowel, others advise a more expectant approach [15] [16]. Data are very scanty as regards the etiology of LGIB in Yemen. The aim of this study is to determine the etiology of LGIB in our center and to compare it with the results of the others elsewhere.

\section{Materials and Methods}

We included in our study all patients with overt LGIB who presented to our center of gastrointestinal and liver diseases in Ibb city during the period from April 2017 to March 2018. Colonoscopy was avoided in LGIB patients, presenting with severe cardiopulmonary instability so they were excluded from the study. For all patients, a comprehensive history was taken including age, gender, previous history of LGIB, use of aspirin or nonsteroidal anti-inflammatory drugs (NSAIDS). The proposal of the study was approved by the scientific committee of internal medicine department-Taiz University. A verbal informed consent was taken from the patients or their relatives. Lower GI endoscopy was done for all patients included in the study using (PENTAX-EPK-5000 or STORZ). Biopsies were taken if needed. Biopsy specimens were immediately fixed in $10 \%$ neutral buffered formalin processed in ethanol and embedded in paraffin blocks. Biopsies were sectioned by YD-310 microtome into $4 \mu \mathrm{m}$ thick sections. Sections were stained with Hematoxylin and Eosin and examined pathologically. Patient's data were analyzed using SPSS 20 statistical package for social sciences (SPSS Inc., Chicago, Illinois, USA) for Windows 10. Results were written in mean and SD and P value was measured by chi square test and a significant threshold was set at 0.05 .

\section{Results}

\subsection{Patient Characteristics}

During the study period, we had 122 patients with LGI bleeding, 72 of them 
were males (59\%) and 50 were females (41\%), with male to female ratio 1.4:1. The age ranged between 5 and 82 years, with a mean age of $45.83 \pm 17.99$ years. The mean age for males was $46.69 \pm 18.12$ and was of $44.58 \pm 17.98$ for females (Table 1).

\subsection{Clinical Manifestations}

The most common clinical manifestations of our studied patients were hematochezia in $72.1 \%$, abdominal pain in $51.7 \%$, diarrhea in $43.3 \%$, pallor and anemia in $40.2 \%$, weight loss in $39.3 \%$, constipation in $16.4 \%$, bloody diarrhea in $16.4 \%$, and melena in 5.7\% (Table 2).

Indications of colonoscopy and colonoscopic findings are shown in (Table 3 and Table 4).

There were no significant statistical differences between males and females regarding the colonoscopic findings in our studied patients $(\mathrm{P}$ value $>0.05)$ (Table 4).

Table 1. Distribution of subjects according to their age and gender $(\mathrm{n}=122)$.

\begin{tabular}{|c|c|c|c|c|c|c|}
\hline \multirow{3}{*}{$\begin{array}{c}\text { Age in years } \\
\leq 20\end{array}$} & \multirow{2}{*}{\multicolumn{2}{|c|}{$\frac{\text { Male }}{\mathrm{n}(\%)}$}} & \multirow{2}{*}{\multicolumn{2}{|c|}{$\frac{\text { Female }}{\mathrm{n}(\%)}$}} & \multirow{2}{*}{\multicolumn{2}{|c|}{$\frac{\text { Total }}{\mathrm{n}(\%)}$}} \\
\hline & & & & & & \\
\hline & 7 & (9.7) & 5 & (10) & 12 & $(9.8)$ \\
\hline $21-40$ & 22 & $(30.6)$ & 18 & (36) & 40 & (32.8) \\
\hline $41-60$ & 25 & $(34.7)$ & 17 & (34) & 42 & (34.4) \\
\hline$\geq 60$ & 18 & (25) & 10 & (20) & 28 & (23) \\
\hline Total & 72 & $(100)$ & 50 & (100) & 122 & (100) \\
\hline
\end{tabular}

Table 2. Distribution of subjects according to their clinical presentation $(\mathrm{n}=122)$.

\begin{tabular}{|c|c|c|}
\hline Variables & No. & $\%$ \\
\hline Hematochezia & 88 & 72.1 \\
\hline Abdominal Pain & 63 & 51.7 \\
\hline Diarrhea & 53 & 43.4 \\
\hline Anemia & 49 & 40.2 \\
\hline Loss of weight & 48 & 39.3 \\
\hline Anal pain & 39 & 32 \\
\hline Tenesmus & 36 & 29.5 \\
\hline Bloody diarrhea & 20 & 16.4 \\
\hline Constipation & 20 & 16.4 \\
\hline Melena & 7 & 5.7 \\
\hline Hematochezia \& melena & 7 & 5.7 \\
\hline
\end{tabular}


Table 3. Indications for colonoscopy among studied patients $(\mathrm{n}=122)$.

\begin{tabular}{ccc}
\hline Indication & No. & $\%$ \\
\hline Hematochezia & 88 & 72.1 \\
Bloody diarrhea & 20 & 16.4 \\
Melena & 7 & 5.7 \\
Hematochezia \& melena & 7 & 5.7 \\
Total & 122 & 100 \\
\hline
\end{tabular}

Table 4. Distribution of subjects according to their colonoscopic findings $(n=122)$.

\begin{tabular}{|c|c|c|c|c|c|c|c|}
\hline \multirow{2}{*}{$\begin{array}{c}\text { Colonoscopic findings } \\
\text { Hemorrhoids }\end{array}$} & \multicolumn{2}{|c|}{$\begin{array}{l}\frac{\text { Male }}{\mathrm{n}(\%)} \\
72(59)\end{array}$} & \multicolumn{2}{|c|}{$\begin{array}{c}\frac{\text { Female }}{\mathrm{n}(\%)} \\
50(41)\end{array}$} & \multicolumn{2}{|c|}{$\begin{array}{c}\frac{\text { Total }}{\mathrm{n}(\%)} \\
122(100)\end{array}$} & \multirow{2}{*}{$\begin{array}{l}\text { P value } \\
0.15\end{array}$} \\
\hline & 21 & $(29.2)$ & 9 & $(18)$ & 30 & $(24.6)$ & \\
\hline Colorectal cancer & 13 & $(18.1)$ & 11 & $(22)$ & 24 & $(19.7)$ & 0.59 \\
\hline Nonspecific colitis & 10 & $(13.9)$ & 9 & $(18)$ & 19 & $(15.6)$ & 0.53 \\
\hline IBD & 5 & $(6.9)$ & 5 & $(10)$ & 10 & $(8.2)$ & 0.54 \\
\hline Anal fissure & 2 & $(2.8)$ & 3 & (6) & 5 & $(4.1)$ & 0.37 \\
\hline Rectal ulcers & 3 & $(4.3)$ & 1 & (2) & 4 & (3.3) & 0.50 \\
\hline Polyps & 2 & $(2.8)$ & 1 & (2) & 3 & $(2.5)$ & 0.78 \\
\hline Diverticulosis & 3 & $(4.2)$ & 0 & 0 & 3 & (2.5) & 0.14 \\
\hline Combined causes & & & & & & & 0.06 \\
\hline Piles \& colitis & 8 & $(11.6)$ & 4 & $(8.2)$ & 12 & $(10.4)$ & \\
\hline Piles \& anal fissure & 0 & 0 & 2 & $(4.1)$ & 2 & (1.7) & \\
\hline Anal fissure $\&$ colitis & 1 & $(1.4)$ & 1 & $(2.1)$ & 2 & (1.7) & \\
\hline Normal colonoscopy & 4 & $(5.6)$ & 4 & (8) & 8 & $(6.6)$ & 0.59 \\
\hline Total & 72 & $(100)$ & 50 & $(100)$ & 122 & $(100)$ & 0.73 \\
\hline
\end{tabular}

\section{Discussion}

LGIB is a significant cause of morbidity and mortality particularly in the elderly worldwide [6] [10]. It is also one of the most common gastrointestinal indications for hospital admission [6]. The incidence increases with age and is more common in men than women (Potter and Sellin, 1988) [5].

In developed countries, the most common causes of LGI bleeding are colon diverticulosis, followed by colonic tumors including polyps or cancer, colitis and anorectal disorders [3]. The picture in the developing countries is different as hemorrhoids being the most of the cases in many published studies from different parts of the world [6] [9] [11] [12]. Meanwhile, diverticulosis and colonic tumors are less commonly encountered owing to high dietary fibers, low animal fats, and protein in developing countries. In our country data regarding the colonoscopic findings in lower GI bleeding are scarce. 
We had 122 cases with LGI bleeding collected in one year period, 72 cases were males and 50 cases were females with male:female ratio was 1.4:1 (Table 1). This slight male predominance is in concordance with what is known in the global literature and most of the studies from different parts of the world [5] [6] [17]. The indications for colonoscopy in our study were; haematochezia in 88 cases $(72.1 \%)$, melena in 7 cases $(5.7 \%)$ and both in 7 cases $(5.7 \%)$, and bloody diarrhea 20 cases $(14.4 \%)$ (Table 3 ). This aspect is similar to a study conducted by Dar IA et al., from Jammu and Kashmir [18].

The other clinical manifestations of our patients were abdominal pain in 63 cases $(51.7 \%)$, diarrhea in 53 cases $(43.4 \%)$, anemia in 49 cases $(40.2 \%)$, weight loss in 48 cases (39.3\%) and constipation in 20 cases (16.4\%) (Table 2).

Findings at colonoscopy in our study were; hemorrhoids in 44 cases (36.7\%), colorectal cancer in 24 cases (19.7\%) more than $90 \%$ of these tumors were located in the left colon, nonspecific colitis in 19 cases (15.6\%), inflammatory bowel disease in 10 cases $(8.2 \%)$, anal fissure in 9 cases $(7.5 \%)$, rectal ulcers in 4 cases $(3.3 \%)$, polyps and diverticulosis in 3 cases $(2.5 \%)$ each and normal colonoscopic findings in 8 cases (6.6\%) (Table 4). Hemorrhoids were the commonest cause of LGIB in this study similar to data from other neighboring countries, and some regions in Asia and Africa [6] [17] [19] [20] [21]. Expectantly our results are different from the pattern of LGIB in the Western world where diverticular disease, ischemic colitis, colorectal cancer and angiodysplasias are the common findings at colonoscopy [3] [22] [23]. The only exception is colorectal cancer which ranked as the second commonest finding and this is in Contrary to the general belief that colorectal cancer is not common in our environment, but with the availability of colonoscopy, this had been debunked as shown in this study.

Finally, one of the limitations of our study is that it was a single clinic based study and it was limited to one year period so extension of this study over several years will give us a larger and more representative sample, and more accurate conclusions to be drawn.

\section{Conclusion}

Hemorrhoids followed by colorectal cancer are the commonest colonoscopic findings in our study. Further larger, longitudinal and/or multicenter studies are needed to draw a definitive conclusion in our community.

\section{References}

[1] Zuccaro, G. (1998) Management of the Adult Patient with Acute Lower Gastrointestinal Bleeding. American College of Gastroenterology. Practice Parameters Committee. American Journal of Gastroenterology, 93, 1202-1208. https://doi.org/10.1111/j.1572-0241.1998.00395.x

[2] Hreinsson, J.P. (2013) Lower Gastrointestinal Bleeding: Incidence, Etiology, and Outcomes in a Population-Based Setting. European Journal of Gastroenterology \& Hepatology, 25, 37-43. https://doi.org/10.1097/MEG.0b013e32835948e3 
[3] Mark, F., Lawrence, S.F. and Lawrence, J.B. (2016) Sleisenger and Fordtran's Gastrointestinal and Liver Disease. $10^{\text {th }}$ Edition, Vol. 1, Saunders, Philadelphia, 320-328.

[4] Lewis, J.D., Brown, A., Locallo, A.R. and Shwartz, J.S. (2002) Initial Evaluation of Rectal Bleeding in Young Persons: A Cost Effectiveness Analysis. Annals of Internal Medicine, 136, 99-110. https://doi.org/10.7326/0003-4819-136-2-200201150-00007

[5] Potter, G.D. and Sellin, J.H. (1988) Lower Gastrointestinal Bleeding. Gastroenterology Clinics of North America, 17, 341-355.

[6] Akande, O.A., Ebenezer, A.A., Olusoji, A.S. and Ekemini, U. (2014) Lower Gastrointestinal Bleeding: Spectrum of Colonoscopy Findings in Ado-Ekiti, Nigeria. International Journal of Medicine and Medical Sciences, 6, 128-133. https://doi.org/10.5897/IJMMS2014.1031

[7] Laine, L., Yang, H., Chang, S.C. and Datto, C. (2012) Trends for Incidence of Hospitalization and Death Due to GI Complications in the United States from 2001 to 2009. The American Journal of Gastroenterology, 107, 1190-1195.

https://doi.org/10.1038/ajg.2012.168

[8] Kevin, A.G. and Dennis, M.J. (2013) Lower GI Bleeding: Epidemiology and Management. Current Gastroenterology Reports, 15, 1-2.

[9] Ibrahim, M.A., Thamer, A.A., Toufic, S. and Adnan, A. (2016) Lower Gastrointestinal Bleeding in Saudi Patients: A Retrospective Longitudinal Study. Journal of Gastrointestinal \& Digestive System, 6, 1-4.

[10] Raju, H.B., Santosh, H., Ravindra, K., Ashray, K. and Deebanshu (2017) Etiological Profile of Patients Presenting with Lower Gastrointestinal Bleeding at Tertiary Care Hospital at Belagavi: A Cross Sectional Study. International Journal of Advances in Medicine, 4, 1429-1433. https://doi.org/10.18203/2349-3933.ijam20174297

[11] Longstreth, G.F. (1997) Epidemiology and Outcome of Patients Hospitalized with Acute Lower Gastrointestinal Hemorrhage: A Population-Based Study. The American Journal of Gastroenterology, 92, 419-424.

[12] Attique-ur, R.J., Rahid, G., Rania, H., Adil, N.K. and Zabiullah, L.K. (2017) Causes of Lower Gastrointestinal Bleeding on Colonoscopy. Journal of Ayub Medical College Abbottabad-Pakistan, 29, 468-470.

[13] Moayyedi, P. and Ford, A. (2002) Recent Developments in Gastroenterology. BMJ, 325, 1399-13402. https://doi.org/10.1136/bmj.325.7377.1399

[14] Alobaidi, Q.A., Al-shammari, A.J. and Al-Faham, A.M. (2018) Colonoscopy Finding of Lower Gastrointestinal Bleeding (LIGB) in AlSeder Medical City (in Al-Najaf)/Iraq. Journal of Pharmaceutical Sciences \& Research, 10, 839-842.

[15] Richter, J.M., Christensen, M.R., Kaplan, L.M. and Nishioka, N.S. (1995) Effectiveness of Current Technology in the Diagnosis and Management of Lower Gastrointestinal Hemorrhage. Gastrointestinal Endoscopy, 41, 93-98. https://doi.org/10.1016/S0016-5107(05)80588-7

[16] Imtiyaz, A.D., Waseem, R.D., Mushtaq, A.K., Basharat, A.K., Najeeb, U.S., Moomin, H., Faheem, A., Manzoor, A.W., Muzamil, L. and Jaswinder, S.S. (2015) Etiology, Clinical Presentation, Diagnosis and Management of Lower Gastrointestinal Bleed in a Tertiary Care Hospital in India: A Retro-Prospective Study. Journal of Digestive Endoscopy, 6, 101-108.

[17] Olookoba, A.B., Bojuwoye, M.O. and Obateru, O.A. (2013) Lower Gastrointestinal Bleeding in Ilorin, Nigeria. The Egyptian Journal of Surgery, 32, 281-285.

[18] Dar, I.A., Dar, W.R., Khan, M.A., Kasana, B.A., Sofi, N.U., Hussain, M., et al. (2015) 
Etiology, Clinical Presentation, Diagnosis and Management of Lower Gastrointestinal Bleed in a Tertiary Care Hospital in India: A Retroprospective Study. Journal of Digestive Endoscopy, 6, 101-109. http://www.jdeonline.in/

[19] Alatise, O.I., Arigbabu, A.O., Agbakwuru, E.A., Lawal, O.O., Ndububa, D.A. and Ojo, O.S. (2012) Spectrum of Colonoscopy Findings in Ile-Ife Nigeria. The Nigerian Postgraduate Medical Journal, 19, 219-224.

[20] Dakubo, J.C.B., Kumoji, R., Naaeder, S.B. and Clegg-Lamptey, J. (2008) Endoscopic Evaluation of the Colorectum in Patients Presenting with Haematochaezia at Korle-Bu Teaching Hospital Accra. Ghana Medical Journal, 42, 33-37.

[21] Fernández, A.C., García, L.E.J., Fuentes, F.M., Chaparro, D., Pinto, C., Elkipe, V., et al. (2010) Management of Lower Gastro-Intestinal Bleeding in the Emergency Department Short-Stay Unit. Emergencias, 22, 269-274.

[22] Strate, L.L. (2005) Lower GI Bleeding: Epidemiology and Diagnosis. Gastroenterology Clinics of North America, 34, 643-664. https://doi.org/10.1016/j.gtc.2005.08.007

[23] Georgia, D., Christos, K., Anastasia, K., Georgios, S., Georgios, T., Vasileios, T., Christos, T., Vasiliki, N. and Konstantinos, T. (2017) Acute Lower Gastrointestinal Bleeding: Characteristics and Clinical Outcome of Patients Treated with an Intensive Protocol. Gastroenterology Research, 10, 352-358.

https://doi.org/10.14740/gr914w 